Case Report

\title{
ANTERIOR APPROACH CELIAC PLEXUS NEUROLYSIS FOR A PATIENT WITH NECROTISING FASCIITIS OF THE BACK
}

\author{
Manjunath Chikkapillappa Abloodu', Vinayak Seenappa Pujari², Tejesh Anandaswamy \\ Channasandra ${ }^{3} \&$ Yatish Bevinaguddaiah ${ }^{4}$ \\ ${ }^{1-4}$ Associate Professors, Department of Anaesthesiology, M S Ramaiah M edical College and Hospitals, \\ New BEL road, M SR Nagar, Bangalore, Karnataka, India. \\ Correspondence : \\ Vinayak P S \\ Associate Professor, Department of Anaesthesiology, M S Ramaiah M edical College and Hospitals, New BEL road, \\ MSR Nagar, Bangalore 560054, Karnataka, India. \\ Mobile : +91 8040502860 E-mail : drvinayak@outlook.com
}

\begin{abstract}
:
Celiac plexus block is a time tested method for management of pain. It is conventionally done via posterior approach. We report successful use of anterior celiac plexus to manage pain in a case of chronic pancreatitis with necrotising fasciitis of the back.
\end{abstract}

Keywords: Anterior celiac plexus block; Necrotising fasciitis; Fluoroscopy; Neurolysis; Chronic Pancreatitis

\section{Introduction:}

Pancreatitis is a serious condition that manifests due to inflammation of the pancreas. It results in pain localized to the upper-to-middle abdomen and may radiate to the back. Conventional treatment strategies for acute pancreatitis include fasting and parental feeding, fluid therapy, and pain management with narcotics for severe pain or nonsteroidal anti-inflammatories for milder cases. A celiac plexus block (CPB) is a time tested method for management of pain in patients with chronic abdominal pain of celiac ganglion origin. Its role in the control of pancreatic cancer pain is well established, but the benefit in chronic pancreatitis pain is controversial ${ }^{[1]}$ Conventionally it is performed via a posterior approach with fluoroscopic or CT guidance. ${ }^{[2]}$ There are There are very few reports of anterior approach for neurolytic block of the celiac plexus using fluoroscopy. ${ }^{[3,4]}$ We report the successful use of fluoroscopic guided anterior approach

Access this article online Quick Response Code

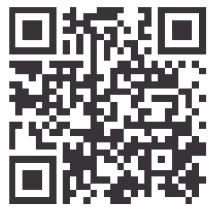

celiac plexus block in a patient with chronic pancreatitis and necrotising fasciitis of the back.

\section{Case History :}

A 40 year old male who was a known case of chronic pancreatitis of probable alcoholic origin and diabetes mellitus presented with extensive necrotising fasciitis of the back. He underwent debridement of necrotising fasciitis twice over a period of one week under general anaesthesia. During his postoperative course he developed severe pain abdomen due to aggravation of his chronic pancreatitis. The patient had severe pain and sleep disturbances. His medication included oral Paracetamol 325M G and Tramadol $375 \mathrm{mg}$ combination $6^{\text {th }}$ hourly and amitryptyline $10 \mathrm{mg}$ bd. His pain was not relieved even by addition of fenatanyl $25 \mathrm{mcg} /$ hour intravenous infusion. Thoracic epidural and celiac plexus block by posterior approach for pain relief were contraindicated due to local infection (Fig 1). Hence, an anterior approach to celiac plexus block using fluoroscopy was planned after obtaining written informed consent.

The patient was kept nil orally for 6hours. In the operating theatre, routine monitoring was initiated. Under strict asepsis cutaneous puncture site marked $1.5 \mathrm{~cm}$ below and $1.5 \mathrm{~cm}$ to the left of the xiphoid process and the puncture site was infiltrated with $2 \mathrm{ml}$ of $1 \%$ lidocaine. A 22-gauge, $15-\mathrm{cm}$ long spinal needle was introduced through the anaesthetised area under fluoroscopic guidance in anterior posterior view. Fig 2The needle was directed caudally and towards the midline and advanced till its tip was positioned at the upper part of $\mathrm{L} 1$ vertebra in the midline(Fig $2 \mathrm{~A}$ ). A 
$90^{\circ}$ lateral fluoroscopic view was then obtained to place the needle tip approximately $1.5 \mathrm{~cm}$ anterior to the $\mathrm{L} 1$ vertebral body. After confirming a negative aspirate for blood, the needle position was confirmed with injection of $2 \mathrm{ml}$ water-soluble contrast (Fig 2B). In the anterior posterior view, the contrast dye must be in the midline and concentrated around vertebral bodies T12 and L1. The contrast dye should not spread beyond the contours of the vertebral bodies. In the lateral view, a smooth contour of the dye should be in front of the vertebral bodies. A diagnostic block with $10 \mathrm{ml} 1 \%$ lidocaine resulted in more

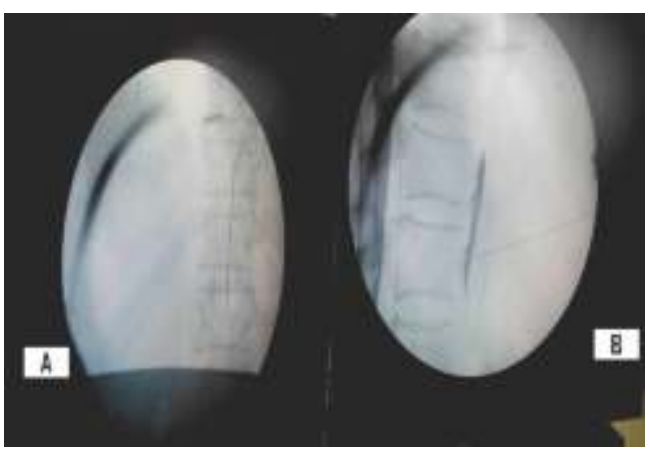

Figure 1: Photo showing necrotising fasciitis of the back contraindicating conventional posterior approach to celiac plexus.

\section{Discussion :}

The percutaneous anterior approach to the celiac plexus was advocated early in this century, only to be abandoned because of the high incidence of complications. The availability of fine needles, improvements in imaging technology has led to renewed interest in the anterior approach to the celiac plexus. Extensive experience with percutaneous transabdominal biopsy has confirmed the relative safety of this approach and has provided the rationale for anterior celiac plexus block. ${ }^{[5]}$

Celiac plexus block performed via an anterior approach has several advantages over a posterior approach, including shorter procedure time, less discomfort to the patient, and less risk of neurologic complications. ${ }^{[5]}$ Although initially coeliac plexus blocks were performed without imaging guidance, computed tomography (CT) is frequently used. ${ }^{[6]}$ Ultrasound, fluoroscopy and endoscopic ultrasound are also beingused. than $50 \%$ pain relief after 5 minutes. Celiac plexus neurolysis was then performed with $20 \mathrm{ml}$ of absolute alcohol. As the needle was withdrawn, $3 \mathrm{~mL}$ of $0.25 \%$ bupivacaine was injected. The patient was haemodynamically stable throughout the procedure. Post procedure the patient had excellent pain relief he was monitored in the PACU for 2 hours, following which he was transferred to the ward. However the pain assessment after 24 hours, 3 days and one week later, the patient had more than $50 \%$ pain relief and was comfortable with only oral Paracetamol with Tramadol combination $8^{\text {th }}$ hourly.

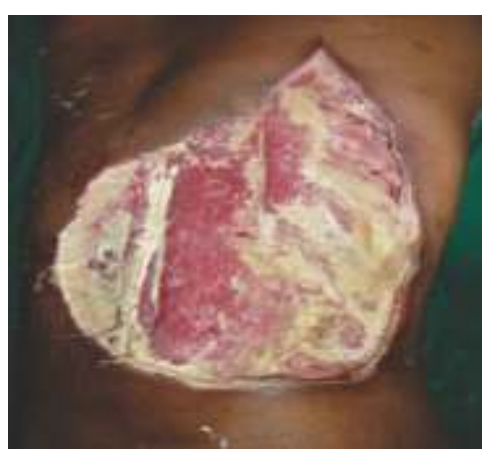

Figure 2 : A Fluroscopic image of needle placement in AP view. B Fluoroscopic image of needle placement and dye spread in lateral view.

Most authors have described and evaluated the procedure via a posterior approach, usually under fluoroscopic guidance. However, conventional posterior approach for celiac plexus block cannot be used in patients, whose anatomy is distorted or those having infection at the site of injection as in our case.

Only few authors have reported using fluoroscopy for anterior approach. ${ }^{[3,4]}$ The advantages of the anterior approach to blocking the celiac plexus include relative ease, speed, and reduced periprocedural discomfort as compared with the posterior techniques. ${ }^{[7]}$ Also patients need not remain prone for a long time, which can be a distressing for patients suffering from intra-abdominal pain. The supine position is also much more comfortable for patients with ileostomies and colostomies. The anterior approach to a celiac plexus block requires only one needle and thus has the advantage of single puncture, resulting in less discomfort to the patient, and use of a smaller volume 
of neurolytic agent. Furthermore, the needle does not impinge on either periosteum, nerve roots or pass through the paraspinous musculature. The precrural needle placement carries less risk of accidental neurologic injury related to retrocrural spread of drug to somatic nerve roots, epidural or subarachnoid spaces. ${ }^{[7]}$

Local abdominal and back pain during or immediately after a celiac plexus block has been reported commonly because of the ablative effect of the neurolytic agent. Other common self-limiting complication is diarrhea occurs due to sympathetic blockade and unopposed parasympathetic efferent influence after the block, and usually resolves in around 48 hours. Orthostatic hypotension may occur due to loss of sympathetic tone and dilated abdominal vasculature Neurologic complications such as paraplegia, leg weakness, sensory deficits, and paresthesias have been reported.

Complications related to puncture of the liver, stomach, pancreas and bowels are rare as fine needles are used. Other rare complications are impotence, gastroparesis, superior mesenteric vein thrombosis, chylothorax, aortic pseudo aneurysm, aortic dissection, and hemorrhage.

In conclusion the fluoroscopic guided anterior celiac plexus block is a safe and economical alternative to conventional posterior and CT guided celiac plexus block.

\section{References:}

1. Leung JWC, Bowen Wright M, Aveling W. Coeliac plexus block for pain in pancreatic cancer and chronic pancreatitis. British Journal of Surgery. 1983;70(12):730-732.

2. Moore DC, Bush WH, Bumett LL. Celiac plexus block: a roentgenographic, anatomic study of technique and spread of solution in patients and corpses. AnesthAnalg1981:60:369-379.

3. Schild H, Gunther A, Hoffman J, Goedecke A. CT-gesteurerte Blockade des Plexus coeliacusmitventralemZugang. ROFO FortschGebRontgenstrNeuenBildgebVerfahr 1983;1 39:202-205.

4. Muehle C, vonSonnenberg E, Casota G, Wittich GA, Potansky AM. Radiographicatly guided alcohol block of the celiac ganglia. Semin Intervent Radiol 1987;4:195-199

5. Romanelli DF, Beckmann CF, Heiss WF. Celiac plexus block: efficacy and safety of the anterior approach. AJR 1993; 160:497-500.

6. Theodosiadis P, Grosomanidis V, Touroutoglou N. Anterior approach to celiac plexus block using CT guidance. The Greek E Jour of Perio Med,2006,4:73-79.

7. Matamala, Sanchez L, Lopez V. Percuta-neous anterior and posterior approach to the celiac plexus: A comparative study using four different techniques. Pain Clin 1992; 5:21-8 